\title{
RASSF10 is an epigenetically silenced tumor suppressor in gastric cancer
}

\author{
ZHENHUA LI $^{1}$, XIAOJING CHANG $^{1,2}$, DONGQIU DAI $^{1,2}$, PENG DENG $^{1,2}$ and QIANG SUN ${ }^{1}$ \\ ${ }^{1}$ Department of Gastrointestinal Surgery and ${ }^{2}$ Cancer Center, The Fourth Affiliated Hospital, \\ China Medical University, Shenyang, Liaoning 110032, P.R. China
}

Received November 30, 2013; Accepted January 14, 2014

DOI: $10.3892 /$ or.2014.3039

\begin{abstract}
To better understand the role of the N-Terminal Ras association domain family (RASSF) genes in the development of gastric cancer, we examined the expression of RASSF7 and RASSF10 and RASSF10 methylation in gastric cancer. We found that RASSF10 expression was lost in six gastric cancer cell lines, and was rescued by a DNA demethylating agent and a histone deacetylase inhibitor. However, RASSF7 expression was strong in four cancer cell lines as well as in $87 \%$ of primary gastric cancer tissues. In contrast, RASSF7 expression was moderate in the GES-1 cell line and negative in $33.3 \%$ of the corresponding non-cancerous tissues. Analysis of RASSF10 methylation by methylation-specific PCR (MSP) and sequencing revealed that the methylation frequency in primary gastric carcinoma tissues was significantly higher compared to that in adjacent non-carcinoma tissues (61.6 vs. 38.4\%; $\mathrm{P}<0.01)$. The methylation frequency in the tumor with invasion depth at T3 and T4 was significantly higher compared to that with invasion depth at T1 and T2 (67.1 vs. $37.5 \%$; $\mathrm{P}<0.05)$. Hypermethylation of RASSF10 was found in the patients with lymph node metastasis, compared to those with unaffected lymph nodes (68.8 vs. $40.9 \%$; $\mathrm{P}<0.05)$. Among the 4 gross types of the Borrmann classification, i.e. EGC, Borrmann I, Borrmann II, Borrmann III and Borrmann IV, the last one was more frequently methylated (85.7 vs. $56.9 \%$; $\mathrm{P}<0.05)$. The present study revealed that RASSF10 is an epigenetically silenced gene involved in tumor invasion and metastasis in gastric cancer, suggesting that the methylation
\end{abstract}

Correspondence to: Professor Dongqiu Dai, Department of Gastrointestinal Surgery and Cancer Center, The Fourth Affiliated Hospital of China Medical University, Shenyang, Liaoning 110032, P.R. China

E-mail: daidq63@126.com

Abbreviations: RASSF, Ras association domain family; NT, N-terminal; TSG, tumor suppressor gene; MSP, methylation-specific PCR; 5-Aza-dC, 5-aza-2'-deoxycytidine; TIS, transcription initiation site

Key words: gastric cancer, Ras association domain family, tumor suppressor gene, epigenetics, DNA methylation status of RASSF10 may be a useful indicator to predict the malignant degree of gastric cancer.

\section{Introduction}

Despite the overall decreasing rates of incidence and mortality, gastric cancer remains the second most common cause of cancer-related mortality worldwide (1). Currently, prognosis of patients with gastric cancer remains dismal, as patients are often at advanced stages of the disease at diagnosis. This emphasizes the need for novel biomarkers for early diagnosis and more accurate prognosis of gastric cancer. Hypermethylation is an important mechanism underlying inactivation of tumor suppressor genes (TSGs), and has been recognized as one of the most important markers for the identification of novel TSGs and detection of cancer and prediction of prognosis (2-4). Several TSGs including hMLH1, P16, MGMT, APC and Ras association domain family 1 isoform A (RASSF1A) have frequently been reported in gastric cancer (5-9). The identification of novel TSGs that are silenced by tumor-specific methylation in gastric cancer will considerably improve the molecular diagnosis for gastric cancer.

RASSF family members including RASSF1- 6 contain C-terminal RA (of the RalGDS/AF-6 variety) and Sav/RASSF/ Hippo (SARAH) interaction domains. Several RASSF genes that encode prominent tumor suppressors are frequently epigenetically silenced in various types of cancer. The silenced genes are involved in cell death regulation, cell cycle control and microtubule stability (10).

Recently, four other proteins were added to the RASSF family and renamed RASSF7-10; they are divergent and structurally distinct from RASSF1-6, as they contain an RA domain in the N-terminal but lack the SARAH domain (11). These N-terminal RASSF proteins represent a new group of potential Ras effectors, which have important biological functions (12). RASSF7 plays an essential role in the regulation of microtube organization and mitotic progression $(11,13)$, and is upregulated in several types of cancer (14-16). Expression of RASSF7 could also be upregulated by hypoxia $(17,18)$. Upon stress, RASSF7/N-Ras could promote cell survival through the inhibition of mitogen-activated protein kinase kinase 7 (MKK7)/c-Jun N-terminal kinase (JNK) mediated signaling pathway. However, with prolonged stress, the RASSF7 protein is degraded so as to allow cell death signaling pathways to be 
activated (19). Although there is currently no direct evidence to support that expression of RASSF7 promotes tumor formation, the evidence indicates that RASSF7 may act as an oncogene in tumorigenesis. RASSF8, another NT-RASSF member identified as a tumor suppressor in lung adenocarcinoma and male germ cell tumor, plays an important role in suppressing tumor metastasis by regulating the Wnt and NF- $\mathrm{B}$ signaling pathways (20-22). Notably, RASSF7 and RASSF8 have been shown to be required for necroptosis, a regulated form of necrosis distinct from apoptosis, in mice (23). RASSF10 contains two isoforms, known as long form (RASSF10-LF) and short form (RASSF10-SF), according to different transcription initiation sites (TIS) as described in Fig. 1A. RASSF10 has also been identified as a candidate TSG and is frequently downregulated by DNA hypermethylation in human cancers (24-27). Direct evidence obtained from a glioma study confirmed the role of RASSF10 in the suppression of tumor growth and cell proliferation (26). It was shown that frequent hypermethylation of RASSF10 promoter was associated with tumor metastasis $(25,27)$, and RASSF10 methylation is an independent prognostic factor associated with poor progression-free survival and overall survival. RASSF10 methylation occurred in early stages of secondary glioblastoma development (26), suggesting that tumor-specific methylation of RASSF10 might act as valuable biomarkers for the detection of cancer and the prediction of prognosis.

To date, whether RASSF10 is downregulated through DNA methylation in gastric cancer remains unknown. Therefore, in the present study, we examined the expression of both RASSF7 and RASSF10 in gastric cancer and performed a comparative analysis of RASSF7 and RASSF10 expression. We also evaluated the status of RASSF10 methylation in gastric cancer, using both methylation-specific PCR (MSP) and sequencing, and analyzed the correlation between RASSF10 methylation with clinicopathological changes.

\section{Materials and methods}

Tissues and cell lines. Tumor specimens including 86 of gastric cancer, 1 of pancreatic cancer and 1 of rectal cancer were obtained from patients with gastric carcinoma who underwent surgery at the Cancer Institute, China Medical University. All samples used for methylation analysis included carcinoma and adjacent non-carcinoma tissues. An additional 54 pairs of primary gastric carcinoma and adjacent non-carcinoma tissues were used for expression analysis. Six gastric cancer cell lines, SGC7901, BGC823, MGC803, AGS, MKN45 and HGC27, and one normal gastric mucosa cell line, GES-1, were obtained from the Institute of Biochemistry and Cell Biology, China Academy of Science, Shanghai, China. Cells were maintained in RPMI-1640 medium (Invitrogen, Carlsbad, CA, USA) supplemented with $10 \%$ fetal bovine serum (FBS) at $37^{\circ} \mathrm{C}$ with $5 \% \mathrm{CO}_{2}$ and $95 \%$ humidity, as recommended.

RT-PCR and quantitative real-time PCR. Total RNA was isolated using TRIzol reagent (Invitrogen) from the cultured cells and 54 pairs of gastric carcinoma and adjacent noncarcinoma tissues for RT-PCR. To determine the methylation status of RASSF10 in gastric cancer, the MKN45 cell line was selected as a model, and was treated with DNA demethylating agent 5-aza-2'-deoxycytidine (5-Aza-dC) (Sigma, St. Louis, MO, USA) and histone deacetylase inhibitor trichostatin A (TSA) (Sigma). The treatments were divided into 5 groups: i) control, ii) 5 -Aza-dC alone $(5 \mu \mathrm{mol} / \mathrm{l})$, iii) 5 -Aza-dC alone $(10 \mu \mathrm{mol} / \mathrm{l})$, iv) TSA alone $(0.3 \mu \mathrm{mol} / \mathrm{l})$, and $\mathrm{v})$ combination of 5 -Aza-dC $(5 \mu \mathrm{mol} / \mathrm{l})$ and TSA $(0.3 \mu \mathrm{mol} / \mathrm{l})$. Cells were treated for $72 \mathrm{~h}$ and the medium containing 5-Aza-dC in groups ii, iii and v was changed every $24 \mathrm{~h}$. In group v, 5-Aza-dC was used for $48 \mathrm{~h}$, followed by TSA treatment for an additional $24 \mathrm{~h}$, while in group iv, cells were treated with TSA only for $24 \mathrm{~h}$. After treatment, cells were harvested for RNA extraction. To eliminate DNA contamination, $1 \mu \mathrm{g}$ of total RNA was incubated in a volume of total $10 \mu 1$ with $1 \mathrm{U}$ DNase I (Fermentas, Burlington, ON, Canada) in $1 \mu 110 \mathrm{X}$ DNase I buffer. After a $30-\mathrm{min}$ incubation at $37^{\circ} \mathrm{C}$, DNase I was inactivated by adding $1 \mu \mathrm{l}$ of $25 \mathrm{mmol} / \mathrm{l}$ EDTA and incubated at $65^{\circ} \mathrm{C}$ for an additional $15 \mathrm{~min}$. Reverse transcription reaction was performed with PrimeScript ${ }^{\mathrm{TM}}$ RT reagent kit (Takara, Beijing, China) using 500 ng RNA from the above prepared RNA sample. The mRNA expression of RASSF10 in a total of seven cell lines was determined by quantitative real-time RT-PCR with SYBR ${ }^{\circledR}$ Premix Ex Taq ${ }^{\text {TM }}$ II (Takara). GAPDH was used as an internal control of RNA integrity and relative mRNA levels were assessed using the $2^{-\Delta \Delta C T}$ method as previously described (28). To compare the expression of RASSF7 and RASSF10, the cDNA of 7 cell lines and 54 pairs of carcinoma and adjacent non-carcinoma tissues was used for conventional RT-PCR, and PCR products were separated by $2 \%$ agarose gel. The PCR reaction was performed with appropriate primers for RASSF10 (primer c-d) (24), RASSF7 and GAPDH as shown in Table I. All samples were submitted to PCR in a total $50 \mu \mathrm{l}$ of reaction mixture, containing $5 \mu \mathrm{l}$ of $10 \mathrm{X}$ buffer, $5 \mu \mathrm{l}$ of $\mathrm{dNTP}, 0.25 \mu \mathrm{l}$ of Dream Taq DNA polymerase $(5 \mathrm{U} / \mu \mathrm{l})$ (Fermentas), $1.0 \mu \mathrm{l}$ each of the sense and antisense primers, $2.0 \mu \mathrm{l}$ of cDNA and $35.75 \mu \mathrm{l}$ of doubledistilled water. Reaction conditions were: pre-denaturation at $95^{\circ} \mathrm{C}$ for $5 \mathrm{~min}$, followed by 35 cycles of $95^{\circ} \mathrm{C}$ for $30 \mathrm{sec}$, $58^{\circ} \mathrm{C}$ for $30 \mathrm{sec}, 72^{\circ} \mathrm{C}$ for $30 \mathrm{sec}$ and final extension at $72^{\circ} \mathrm{C}$ for $10 \mathrm{~min}$.

$R T-P C R$ with primer $a-b$. To determine the isoform of RASSF10 expression, we designed one pair of primers in the consensus region of subtypes (primer c-d), according to the difference between RASSF-LF and RASSF-SF in mRNA, for which detailed information is shown in Fig. 1A. To confirm the expression of RASSF10, we used another pair of primers, in which the forward primer was at the intron and the reverse primer was at the consensus region (primer a-b; Fig. 1A, Table I). The primers were verified using the cDNA from GES-1 cells as PCR template.

DNA extraction and sodium bisulfite modification. Genomic DNA was extracted from frozen tissues and cultured cells by the standard phenol/chloroform procedure. Bisulphate modification was performed as previously described. Briefly, $2 \mu \mathrm{g}$ of genomic DNA in a volume of $50 \mu \mathrm{l}$ was denatured by $\mathrm{NaOH}$ (final concentration, $0.2 \mathrm{~mol} / \mathrm{l}$ ) for $30 \mathrm{~min}$ at $42^{\circ} \mathrm{C}$. The denatured DNA samples were treated with freshly prepared $30 \mu \mathrm{l}$ of hydroquinone $(10 \mathrm{mmol} / \mathrm{l})$ (Sigma) and $520 \mu \mathrm{l}$ of sodium bisulphate $(3.9 \mathrm{~mol} / \mathrm{l}$; $\mathrm{pH} 5.0)$ (Sigma) at $55^{\circ} \mathrm{C}$ for $16 \mathrm{~h}$, 
Table I. Primers for RT-PCR and methylation-specific PCR.

Sequence

Product length (bp)

$\begin{array}{ll}\text { RASSF10 (primer c-d) } & \text { F: 5'-CCATGACCCAGGAGAAACAG-3' } \\ & \text { R: 5'-TGCTGGCGAATTGTGTGGTC-3' } \\ \text { RASSF10 (primer a-b) } & \text { F: 5'-GGGAACAGGGCTAGTGCAG-3' } \\ & \text { R: 5'-TCTCTTCCTGGCAGATCCAC-3' } \\ \text { RASSF7 } & \text { F: 5'-AAGTGGTCATCGCACTAGCC-3' } \\ & \text { R: 5'-TCAGGACAAACTGGACATCG-3' } \\ \text { RASSF10-M } & \text { F: 5'-GGGTATTTTGGGTAGAGTTAGAGC-3' } \\ & \text { R: 5'-AAACAAACTAAAAAACGACTACGAC-3' } \\ \text { RASSF10-U } & \text { F: 5'-GGGTATTTTGGGTAGAGTTAGAGTG-3' } \\ & \text { R: 5'-AAACAAACTAAAAAACAACTACAAC-3' } \\ \text { GAPDH } & \text { F: 5'-CATGAGAAGTATGACAACAGCCT-3' } \\ & \text { R: 5'-AGTCCTTCCACGATACCAAAGT-3' }\end{array}$

R: 5'-AGTCCTTCCACGATACCAAAGT-3

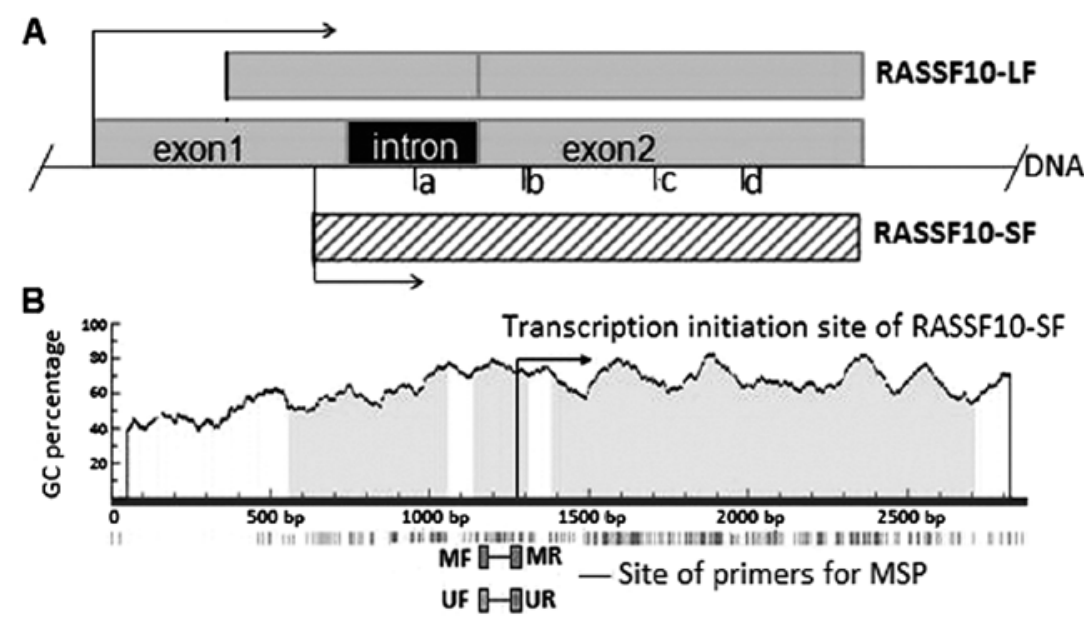

Figure 1. Characteristics of RASSF10. (A) Schematic model of long form (LF) and short form (SF). Arrows mark the two putative transcription initiation sites (TIS) which code RASSF-LF (grey boxes) and RASSF10-SF (striped box) respectively. ' $a$ ' and 'b' represent the forward and reverse sites of primer a-b used for RT-PCR. 'c' and 'd' represent the forward and reverse sites of primer c-d. (B) The RASSF10 gene contains a large CpG island, which spans across the promoter and coding region. Arrows mark the TIS of RASSF-SF and the primer sites for methylation-specific PCR (MSP) in the present study.

followed by a stop reaction using $\mathrm{NaOH}$ (final concentration, $0.3 \mathrm{~mol} / \mathrm{l}$ ) at room temperature for $5 \mathrm{~min}$. Finally, modified DNA was recovered using Wizard DNA Clean-Up System (Promega, Madison, WI, USA), according to the manufacturer's instructions and precipitated using a combination of glycogen, ammonium acetate and ethanol, followed by a wash using 70\% ethanol. The pellet of recovered DNA was resuspended in $15 \mu 1 \mathrm{TE}$ buffer.

MSP. The methylation status of RASSF10 was determined by MSP using bisulfite-converted DNA as template. Total reaction mixture volume was $50 \mu 1$, containing $5 \mu \mathrm{l}$ of $10 \mathrm{X}$ buffer, $5 \mu \mathrm{l}$ of $\mathrm{dNTP}, 0.25 \mu \mathrm{l}$ of Dream Taq DNA polymerase $(5 \mathrm{U} / \mu \mathrm{l})$ (Fermentas), $1 \mu \mathrm{l}$ each of the sense and antisense primers, $2.0 \mu \mathrm{l}$ of DNA and $35.75 \mu \mathrm{l}$ of double-distilled water. Reaction conditions were: pre-denaturation at $95^{\circ} \mathrm{C}$ for $5 \mathrm{~min}$, followed by 40 cycles of $95^{\circ} \mathrm{C}$ for $30 \mathrm{sec}, 56^{\circ} \mathrm{C}$ for $30 \mathrm{sec}, 72^{\circ} \mathrm{C}$ for $30 \mathrm{sec}$, followed by a final extension at $72^{\circ} \mathrm{C}$ for $10 \mathrm{~min}$. The annealing temperature of methylated and unmethylated reaction was at $56^{\circ} \mathrm{C}$. The methyltransferase SssI (New England Biolabs, Ipswich, MA, USA)-treated and untreated cord blood cells from newborn were used as a positive control for methylation or unmethylation, respectively. Double-distilled water was used as the blank control. Methylation-specific (RASSF10-M) and unmethylation-specific (RASSF10-U) primers are listed in Table I. The size of methylation and unmethylation PCR products was $126 \mathrm{bp}$, from the region -120 to +6 relative to the TIS of RASSF10-SF. MSP products were verified by $2 \%$ agarose gel. The accuracy of the verified MSP products was confirmed by sequencing.

Statistical analysis. Statistical analysis was carried out using SPSS 13.0 software. Correlation of DNA methylation and clinicopathological parameters was assessed using the Chi-square test. All reported P-values were two-sided and a P-value $<0.05$ was considered to indicate a statistically significant difference. 


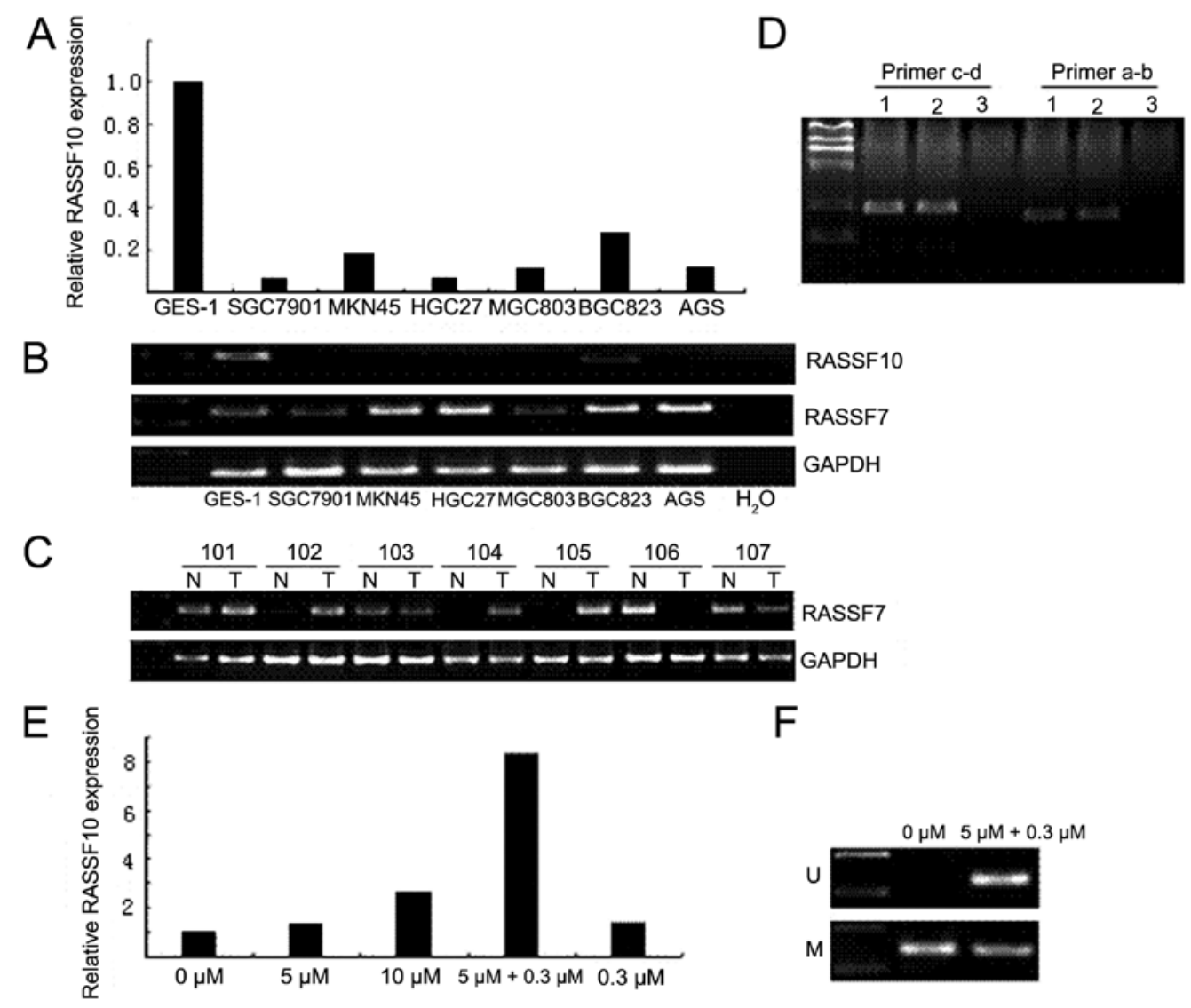

Figure 2. Expression of RASSF7 and RASSF10 in gastric cancer. (A) RASSF10 expression was determined by quantitative real-time PCR. GAPDH was used to normalize the RASSF10 expression. GES-1 was used as the reference. (B) Comparison of RASSF7 and RASSF10 expression in GES-1 and 6 gastric cancer cell lines. As control, RNA integrity was determined based on GAPDH expression and template was replaced by water for blank control. PCR products were separated on $2 \%$ gel. (C) RASSF7 expression in gastric cancer tissues and corresponding non-cancerous tissues. N, adjacent non-carcinoma tissue; T, carcinoma tissue. (D) cDNA amplification for GES-1 cells with primer c-d and primer a-b. The lanes 1, 2 and 3 represent different templates: GES-1 DNA, cDNA and $\mathrm{H}_{2} \mathrm{O}$, respectively. (E) Effect of de-methylating agent on RASSF10 expression in MKN45. The treatment dose was 5-Aza-dC alone (5 or $10 \mu \mathrm{M}$ ), TSA alone $(0.3 \mu \mathrm{M})$ and combination of 5-Aza-dC $(5 \mu \mathrm{M})$ and TSA $(0.3 \mu \mathrm{M})$. Re-expression was measured by quantitative real-time PCR. The untreated group was used as the reference. GAPDH was also used as an internal control of RNA integrity. (F) Comparison of RASSF10 methylation status between untreated and combinatorial treatment groups. $\mathrm{U}$, unmethylation; $\mathrm{M}$, methylation.

\section{Results}

Expression of RASSF7 and RASSF10 in gastric cancer. To evaluate the expression of $\mathrm{N}$-terminal RASSF genes in gastric cancer, the mRNA level of RASSF10 in gastric cancer cell lines was examined by quantitative real-time RT-PCR. The results showed that RASSF10 was strongly expressed in GES-1 cells, while its expression was downregulated in 6 gastric cancer cell lines (Fig. 2A). By contrast, the RASSF7 expression was strong in MKN45, HGC27, BGC823 and AGS, but moderate in GES-1, SGC7901 and MGC803 (Fig. 2B). In addition, $87 \%$ (47/54) of primary gastric cancer tissues exhibited positive RASSF7 expression, whereas $66.7 \%$ (36/54) of corresponding non-cancerous tissues had positive RASSF7 expression ( $\mathrm{P}<0.05)$ (Fig. 2C; Table II). However, the RASSF10 expression in both carcinoma and non-carcinoma tissues was below detectable levels (data not shown). Next, to determine the isoform of RASSF10, we used primer $a-b$ to identify the isoform of the expressed RASSF10 in GES-1 cells. The results indicated that the positive samples detected using the primer $\mathrm{c}-\mathrm{d}$ were the same as those detected with the primer $\mathrm{a}-\mathrm{b}$ in GES-1 cells (Fig. 2D).
Table II. Statistical analysis of RASSF7 expression between carcinoma tissues and adjacent non-carcinoma tissues.

\begin{tabular}{lcccc}
\hline & & \multicolumn{3}{c}{ RASSF7 expression } \\
\cline { 3 - 5 } & $\begin{array}{c}\text { Patient } \\
(\mathrm{n})\end{array}$ & $\begin{array}{c}\text { Positive } \\
(\%)\end{array}$ & $\begin{array}{c}\text { Negative } \\
(\%)\end{array}$ & P-value \\
\hline Non-carcinoma tissue & 54 & $36(66.7)$ & $18(33.3)$ & $<0.05$ \\
Carcinoma tissue & 54 & $47(87.0)$ & $7(13.0)$ & \\
\hline
\end{tabular}

Upregulation of RASSF10 expression after 5-Aza-dC and TSA treatment. To confirm promoter hypermethylation-mediated RASSF10 silencing in gastric cancer, MKN45, a cell line negative for RASSF10 was selected as a model for the re-activation study. After treatment with DNA demethylating agent and histone deacetylase inhibitor, re-expression of RASSF10 was analyzed using quantitative real-time PCR. The result confirmed that the hypermethylation of RASSF10 promoter occurred in MKN45 cells. Re-expression of RASSF10 was induced after treatment of 5-Aza-dC and TSA (Fig. 2E). 

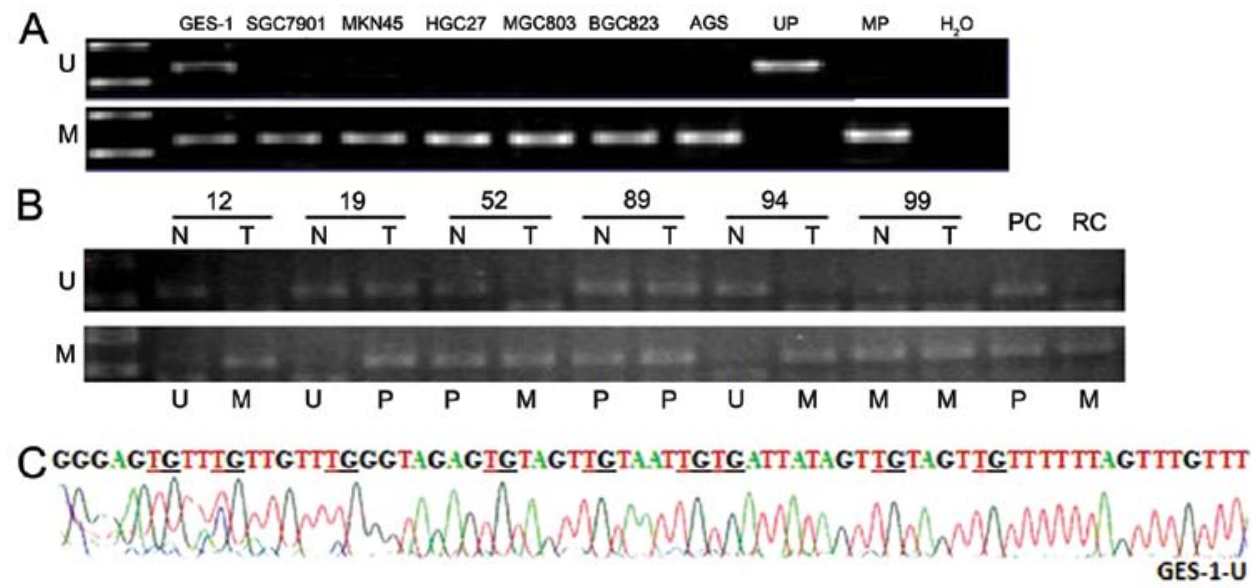

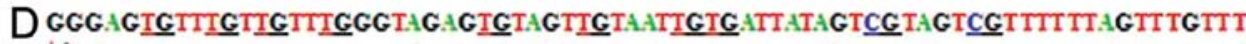

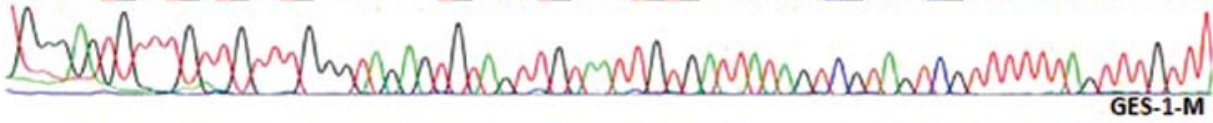

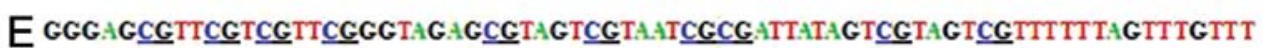

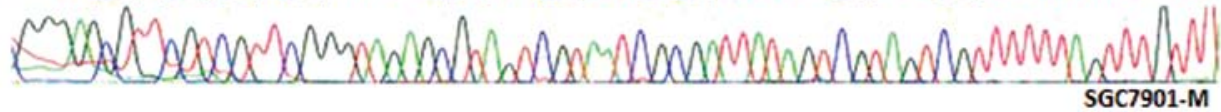

Figure 3. Methylation status of RASSF10 promoter. (A) The methylation status of RASSF10 in GES-1 and 6 gastric cancer cell lines determined by methylation-specific PCR (MSP). U, unmethylation; M, hypermethylation; UP, unmethylation in positive control cells; MP, methylation in positive control cells; $\mathrm{H}_{2} \mathrm{O}$, blank control. (B) The methylation status of RASSF10 in specimens of primary gastric cancer, pancreatic cancer (1 case) and rectal cancer (1 case). N, adjacent non-carcinoma tissue; T, carcinoma tissue; P, partial methylation. (C-E) The sequencing results of MSP products for GES-1 and SGC7901 cells. The underline marks the $\mathrm{CpG}$ sites in original template DNA. The sequenced products were from -66 to +6 relative to the transcription initiation site of RASSF10-SF.

Furthermore, the re-expression level of RASSF10 induced by the combination of 5-Aza-dC and TSA was much higher than that induced by 5-Aza-dC alone or TSA alone, even at the same concentration. Meanwhile, the MSP results showed that both unmethylated and methylated bands existed in the combined treated cells, but unmethylated band did not appear in the control cells (untreated), suggesting that the methylation status of RASSF10 promoter was partially changed after the treatment in MKN45 (Fig. 2F).

Promoter hypermethylation of RASSF10 in gastric cancer. A typical $\mathrm{CpG}$ island (CGI) was found in the region of the RASSF10 gene as shown in Fig. 1B, according to the following criteria: GC content $>55 \%$, ObsCpG/ExpCpG $>0.65$, and length $>500$ bp (http://www.urogene.org/methprimer/index1.html). In the present study, we examined the methylation status of this CGI in gastric cancer by MSP. As shown in Fig. 3A, RASSF10 hypermethylation was detected in all 6 gastric cancer cell lines, but in the GES-1 cell line, only partial methylation was found. To verify our finding from the cell lines, we analyzed the methylation status of RASSF10 promoter in 86 paired samples of primary tissues of gastric carcinoma and adjacent non-carcinoma, 1 sample of pancreatic cancer and 1 sample of rectal cancer (Fig. 3B). To confirm the sufficiency of sodium bisulfite modification, both unmethylated and methylated PCR products of GES-1 (GES-1-U and GES-1-M, respectively) and methylated product of SGC7901 (SGC7901-M) were sent for sequencing and the results are shown in Fig. 3C-E. The present study showed that hypermethylation of RASSF10 promoter was detected in $61.6 \%$ (53/86) of gastric tumor tissues (Table III), and the rest were partial or unmethylated. By contrast, the ratio
Table III. Statistical analysis of RASSF10 methylation status between adjacent non-carcinoma tissues and carcinoma tissues.

\begin{tabular}{|c|c|c|c|c|}
\hline & \multirow[b]{2}{*}{$\begin{array}{c}\text { Patient } \\
\text { (n) }\end{array}$} & \multicolumn{2}{|c|}{$\begin{array}{l}\text { RASSF10 } \\
\text { methylation } \\
\text { status }\end{array}$} & \multirow[b]{2}{*}{ P-value } \\
\hline & & $\begin{array}{l}\mathrm{U}+\mathrm{P} \\
(\%)\end{array}$ & $\begin{array}{c}\mathrm{M} \\
(\%)\end{array}$ & \\
\hline Non-carcinoma tissue & 86 & $53(61.6)$ & $33(38.4)$ & $<0.01$ \\
\hline Carcinoma tissue & 86 & $33(38.4)$ & $53(61.6)$ & \\
\hline
\end{tabular}

U, unmethylation; P, partial methylation; M, hypermethylation.

of hypermethylation was only $38.4 \%$ (33/86) in the adjacent non-carcinoma tissues. Statistical analysis revealed a significant increase of the ratio of RASSF10 hypermethylation in gastric carcinoma tissues, compared with that in the adjacent non-carcinoma tissues $(\mathrm{P}<0.01)$. The foci with size $>10 \mathrm{~cm}$ had a much higher ratio of hypermethylation, compared to those in smaller size ( 91.7 vs. $56.8 \%$; P<0.05) (Table IV). Furthermore, compared with other types (EGC, Borrmann I, Borrmann II and Borrmann III), Borrmann IV was more frequently methylated ( 85.7 vs. $56.9 \%$; $\mathrm{P}<0.05$ ). Correlation analysis of RASSF10 methylation and TNM stage (UICC, version 7, 2009) revealed that the tumor with invasion depth at T3 and T4 had much higher methylation frequency than that with invasion depth at $\mathrm{T} 1$ and $\mathrm{T} 2(67.1$ vs. $37.5 \%$; $\mathrm{P}<0.05)$. In patients with lymph node metastasis (N1, N2 and N3), their tumors had 
Table IV. Correlation of clinicopathological parameters and RASSF10 methylation status in gastric cancer tissues.

\begin{tabular}{|c|c|c|c|c|}
\hline \multirow[b]{2}{*}{ Variables } & \multirow[b]{2}{*}{$\begin{array}{c}\text { Patients } \\
(\mathrm{n}=86)\end{array}$} & \multicolumn{2}{|c|}{$\begin{array}{c}\text { RASSF10 } \\
\text { methylation status }\end{array}$} & \multirow[b]{2}{*}{ P-value } \\
\hline & & $\begin{array}{l}\mathrm{U}+\mathrm{P} \\
(\%)\end{array}$ & $\begin{array}{c}\mathrm{M} \\
(\%)\end{array}$ & \\
\hline Gender & & & & $>0.05$ \\
\hline Male & 60 & $25(41.7)$ & $35(58.3)$ & \\
\hline Female & 26 & $8(30.8)$ & $18(69.2)$ & \\
\hline Age (years) & & & & $>0.05$ \\
\hline$<50$ & 12 & $7(58.3)$ & $5(41.7)$ & \\
\hline$\geq 50$ & 74 & $46(62.2)$ & $28(37.8)$ & \\
\hline Tumor size $(\mathrm{cm})$ & & & & $<0.05$ \\
\hline$<10$ & 74 & $32(43.2)$ & $42(56.8)$ & \\
\hline$\geq 10$ & 12 & $1(8.3)$ & $11(91.7)$ & \\
\hline Histological type & & & & $>0.05$ \\
\hline Mass+nest & 34 & $15(44.1)$ & $19(55.9)$ & \\
\hline Diffuse & 52 & $18(34.6)$ & $34(65.4)$ & \\
\hline Gross type & & & & $<0.05^{\mathrm{a}}$ \\
\hline EGC & 4 & $2(50.0)$ & $2(50.0)$ & \\
\hline Borrmann I & 5 & $3(60.0)$ & $2(40.0)$ & \\
\hline Borrmann II & 2 & $1(50.0)$ & $1(50.0)$ & \\
\hline Borrmann III & 61 & $25(41.0)$ & $36(59.0)$ & \\
\hline Borrmann IV & 14 & $2(14.3)$ & $12(85.7)$ & \\
\hline Invasion depth & & & & $<0.05^{\mathrm{b}}$ \\
\hline $\mathrm{T} 1$ & 4 & $2(50.0)$ & $2(50.0)$ & \\
\hline $\mathrm{T} 2$ & 12 & $8(66.7)$ & $4(33.3)$ & \\
\hline T3 & 15 & $5(33.3)$ & $10(66.7)$ & \\
\hline $\mathrm{T} 4$ & 55 & $18(32.7)$ & 37 (67.3) & \\
\hline $\begin{array}{l}\text { Lymph node } \\
\text { metastasis }\end{array}$ & & & & $<0.05^{\mathrm{c}}$ \\
\hline No & 22 & $13(59.1)$ & $9(40.9)$ & \\
\hline N1 & 21 & $8(38.1)$ & $13(61.9)$ & \\
\hline N2 & 14 & $6(42.9)$ & $8(57.1)$ & \\
\hline N3 & 29 & $6(20.7)$ & $23(79.3)$ & \\
\hline TNM stage & & & & $<0.05^{\mathrm{d}}$ \\
\hline I & 10 & $8(80.0)$ & $2(20.0)$ & \\
\hline II & 22 & $7(31.8)$ & $15(68.2)$ & \\
\hline III & 54 & $18(33.3)$ & $36(66.7)$ & \\
\hline IV & - & - & - & \\
\hline
\end{tabular}

Significant differences: ${ }^{a}$ EGC + Borrmann I + Borrmann II + Borrmann III vs. Borrmann IV, 56.9 vs. $85.7 \%, \mathrm{P}<0.05$; ${ }^{\mathrm{b}} \mathrm{T} 1+\mathrm{T} 2$ vs. T3+T4, 37.5 vs. $67.1 \%, \mathrm{P}<0.05$; ${ }^{\mathrm{N}} \mathrm{N} 0$ vs. $\mathrm{N} 1+\mathrm{N} 2+\mathrm{N} 3,40.9$ vs. $68.8 \%, \mathrm{P}<0.05$; ${ }^{\mathrm{d} I}$ vs. II+III, 20 vs. $67.1 \%, \mathrm{P}<0.05$; U, unmethylation; $\mathrm{P}$, partial-methylation; $\mathrm{M}$, hypermethylation; EGC, early gastric cancer. TNM stage was accordant with the UICC, Version 7 (2009).

a higher frequency of RASSF10 hypermethylation than that in the patients with unaffected lymph nodes (N0), i.e. $68.8 \%$ $(44 / 64)$ of $\mathrm{N} 1+\mathrm{N} 2+\mathrm{N} 3$ vs. $40.9 \%(9 / 22)$ of $\mathrm{N} 0 ; \mathrm{P}<0.05$. For
TNM stage, only $20 \%$ (2/10) of tumors showed hypermethylation of RASSF10 in stage I. However, the total frequency of RASSF10 hypermethylation in stage II and stage III was $67.1 \%$ (51/76), which was significantly higher than the frequency in stage I (67.1 vs. $20 \%$; $\mathrm{P}<0.05)$. No significant differences were found between hypermethylation status and histological type, gender or age.

\section{Discussion}

In recent years, many TSGs have been found to be epigenetically inactivated in gastric cancer, indicating that epigenetic silencing of TSGs is one of the major molecular alterations in the process of gastric carcinogenesis (29). Previously, RASSF10 was identified as a candidate TSG and its expression is frequently silenced by DNA methylation in human cancer (24-27). Our studies also demonstrated that RASSF10 was frequently silenced in gastric cancer through promoter hypermethylation. However, RASSF10 expression in both primary carcinoma tissues and adjacent non-carcinoma tissues was negative, whereas most of the non-carcinoma tissues were chronic gastritis and intestinal metaplasia, which are considered as precancerous lesions. Therefore, our findings indicate that the epigenetic silencing of RASSF10 is a wide and frequent event, which might be a significant aberrance related to RASSF10 function during carcinogenesis. In addition, in the present study, the combination treatment of 5-Aza-dC and TSA in MKN45 cells induced higher RASSF10 expression compared to single agent treatment with either 5-Aza-dC or TSA, suggesting that epigenetic alterations including both DNA hypermethylation and histone deacetylation are involved in the downregulation of RASSF10 expression in gastric cancer.

Emerging evidence has shown that the hypermethylation of TSG promoter is one of the major molecular alterations in cancer development. Methylation of TSGs, such as COX-2, hMLH1 and p16 are rare in the non-neoplastic gastric mucosa including chronic gastritis and intestinal metaplasia, but appear frequently in carcinoma (30). Therefore, the methylation status of p16 may be a useful biomarker for the prediction of the malignant potential of dysplasia, in particular gastric biopsies (31). However, in the present study, 38.4\% (33/86) of adjacent non-carcinoma tissues were hypermethylated. These results may not correctly reflect the actual scenario of RASSF10 methylation in normal gastric mucosa, since most were tissues of chronic gastritis and intestinal metaplasia, which are considered as precancerous lesions. Therefore, we propose that the methylation status of RASSF10 might be used as a biomarker to predict the malignant potential of the gastric precancerous lesions. In fact, the RASSF10 methylation was rarely found in early tumor cases, but in advanced tumors, especially in cases which showed extremely malignant clinicopathological characteristics, such as Borrmann IV, high degree of invasion, cancerous lymph node and large size. The increase in RASSF10 hypermethylation suggests that RASSF10 may be involved in the suppression of tumor invasion and metastasis in gastric cancer. Overall, epigenetic silencing of RASSF10 is associated with the pathogenic development of gastric cancer, and the methylation status of RASSF10 may be used as a biomarker to evaluate the malignant potential of the 
precancerous lesions and malignant degree of tumor in gastric cancer. Thus, we propose that RASSF10 acts as a novel TSG that is frequently inactivated in gastric cancer by the epigenetic alterations including DNA hypermethylation and histone deacetylation.

Previous studies found that RASSF7 expression was upregulated by hypoxia (17-18). In particular, RASSF7/N-Ras could promote cell survival through the inhibition of the mitogenactivated protein kinase kinase 7 (MKK7)/c-Jun N-terminal kinase (JNK) pathway during initial stress. However, in order to activate cell death signaling pathway with prolonged stress, the RASSF7 protein was degraded (19). These findings suggest that RASSF7 plays a role in oxidative stress. Several studies have reported that RASSF7 is upregulated in cancer (14-16). We also observed a similar phenomenon in gastric cancer. Depletion of RASSF7 in HeLa cells inhibited cell growth, although knockdown of RASSF7 did not significantly induce apoptosis (13). Therefore, we speculate that RASSF7 has multiple functions in tumorigenesis, such as promoting mitosis or survival function to protect cancer cells from damage caused by stress. Further investigations are required to clarify the functions of RASSF7 in the development of cancer.

RASSF10 or RASSF10-LF is a 615 amino acid protein encoded by a two exon gene separated by a short intron of 104 bp. A new variant of RASSF10 (RASSF10-SF) was reported by Hesson et al (24), that was found by 5 ' rapid amplification of cDNA ends (RACE) . RASSF10-SF is a single exon gene that has a $5^{\prime}$ untranslated region (5'UTR) of $431 \mathrm{bp}$, a 3'UTR of $478 \mathrm{bp}$ and an open reading frame that encodes a protein of 507 amino acids. To distinguish between the two isoforms by RT-PCR, we designed a pair of primers where the forward primer binds to the so-called intron and reverse primer binds to the consensus region of these two isoform. In the present study, the cDNA of GES-1 was used as a template for PCR amplification. Results showed that the primers were able to amplify the cDNA from GES-1 cells, suggesting that the RASSF gene does not contain the so-called intron and RASSF10-SF is the true isoform in gastric mucosa.

Our results indicated that RASSF10 is a characteristically epigenetically silenced tumor suppressor correlated with invasion and metastasis in gastric cancer and its epigenetic alteration may contribute to the pathogenic development of gastric cancer. RASSF-SF may represent the biologically relevant isoform in human tissues. Exploring the roles of RASSF10 in cancer development will not only increase our understanding of the biology of gastric cancer, but may also enable the methylation status of RASSF10 to be used as a molecular target for diagnosis and therapy. The expression of RASSF7 was negatively correlated with that of RASSF10, suggesting a potential oncogenic role of RASSF7 in gastric cancer. Collectively, the present study revealed a novel tumor suppressor that is silenced by epigenetic mechanisms in gastric cancer and provides insight for further studies on the roles of RASSF7 and RASSF10 in gastric cancer development.

\section{Acknowledgements}

The present study was supported by the National Natural Science Foundation of China (no. 30572162), the Higher Specialized Research Fund for Doctoral Program of the
Ministry of Education of China (no. 20102104110001) and the Liaoning Province Science and Technology Plan Project (no. 2013225021). The authors are grateful to the Institute of General Surgery of China Medical University.

\section{References}

1. Jemal A, Bray F, Center MM, Farley J, Ward E and Forman D: Global cancer statistics. CA Cancer J Clin 61: 69-90, 2011.

2. Jones PA and Baylin SB: The fundamental role of epigenetic events in cancer. Nat Rev Genet 3: 415-428, 2002.

3. Esteller M: Epigenetics in cancer. N Engl J Med 358: 1148-1159, 2008.

4. Jones PA and Baylin SB: The epigenomics of cancer. Cell 128: 683-692, 2007.

5. Fleisher AS, Esteller M, Wang S, et al: Hypermethylation of the hMLH1 gene promoter in human gastric cancers with microsatellite instability. Cancer Res 59: 1090-1095, 1999.

6. Lee YY, Kang SH, Seo JY, et al: Alterations of p16INK4A and p15INK4B genes in gastric carcinomas. Cancer 80: 1889-1896, 1997.

7. Oue N, Shigeishi H, Kuniyasu H, et al: promoter hypermethylation of MGMT is associated with protein loss in gastric carcinoma. Int J Cancer 93: 805-809, 2001.

8. Tsuchiya T, Tamura G, Sato K, et al: Distinct methylation patterns of two $A P C$ gene promoters in normal and cancerous gastric epithelia. Oncogene 19: 3642-3646, 2000.

9. Byun DS, Lee MG, Chae KS, Ryu BG and Chi SG: Frequent epigenetic inactivation of RASSF1A by aberrant promoter hypermethylation in human gastric adenocarcinoma. Cancer Res 61: 7034-7038, 2001

10. Richter AM, Pfeifer GP and Dammann RH: The RASSF proteins in cancer; from epigenetic silencing to functional characterization. Biochim Biophys Acta 1796: 114-128, 2009.

11. Sherwood V, Manbodh R, Sheppard C and Chalmers AD: RASSF7 is a member of a new family of RAS association domain-containing proteins and is required for completing mitosis. Mol Biol Cell 19: 1772-1782, 2008.

12. Sherwood V, Recino A, Jeffries A, Ward A and Chalmers AD: The N-terminal RASSF family: a new group of Ras-associationdomain-containing proteins, with emerging links to cancer formation. Biochem J 425: 303-311, 2009.

13. Recino A, Sherwood V, Flaxman A, et al: Human RASSF7 regulates the microtubule cytoskeleton and is required for spindle formation, Aurora B activation and chromosomal congression during mitosis. Biochem J 430: 207-213, 2010.

14. Mutter GL, Baak JP, Fitzgerald JT, et al: Global expression changes of constitutive and hormonally regulated genes during endometrial neoplastic transformation. Gynecol Oncol 83: 177-185, 2001.

15. Logsdon CD, Simeone DM, Binkley C, et al: Molecular profiling of pancreatic adenocancer and chronic pancreatitis identifies multiple genes differentially regulated in pancreatic cancer. Cancer Res 63: 2649-2657, 2003.

16. Lowe AW, Olsen M, Hao Y, et al: Gene expression patterns in pancreatic tumors, cells and tissues. PLoS One 2: e323, 2007

17. Camps C, Buffa FM, Colella S, et al: hsa-miR-210 is induced by hypoxia and is an independent prognostic factor in breast cancer. Clin Cancer Res 14: 1340-1348, 2008.

18. Liang GP, Su YY, Chen J, Yang ZC, Liu YS and Luo XD: Analysis of the early adaptive response of endothelial cells to hypoxia via a long serial analysis of gene expression. Biochem Biophys Res Commun 384: 415-419, 2009.

19. Takahashi S, Ebihara A, Kajiho H, Kontani K, Nishina H and Katada T: RASSF7 negatively regulates pro-apoptotic JNK signaling by inhibiting the activity of phosphorylated-MKK7. Cell Death Differ 18: 645-655, 2011.

20. Falvella FS, Manenti G, Spinola M, et al: Identification of RASSF8 as a candidate lung tumor suppressor gene. Oncogene 25: 3934-3938, 2006.

21. Korkola JE, Houldsworth J, Chadalavada RS, et al: Downregulation of stem cell genes, including those in a $200-\mathrm{kb}$ gene cluster at $12 \mathrm{p} 13.31$, is associated with in vivo differentiation of human male germ cell tumors. Cancer Res 66: 820-827, 2006.

22. Lock FE, Underhill-Day N, Dunwell T, et al: The RASSF8 candidate tumor suppressor inhibits cell growth and regulates the Wnt and NF- $\mathrm{B}$ signaling pathways. Oncogene 29: 4307-4316, 2010 . 
23. Hitomi J, Christofferson DE, Ng A, et al: Identification of a molecular signaling network that regulates a cellular necrotic cell death pathway. Cell 135: 1311-1323, 2008.

24. Hesson LB, Dunwell TL, Cooper WN, et al: The novel RASSF6 and RASSF10 candidate tumour suppressor genes are frequently epigenetically inactivated in childhood leukaemias. Mol Cancer 8: 42, 2009 .

25. Schagdarsurengin U, Richter AM, Wöhler C and Dammann RH: Frequent epigenetic inactivation of RASSF10 in thyroid cancer. Epigenetics 4: 571-576, 2009.

26. Hill VK, Underhill-Day N, Krex D, et al: Epigenetic inactivation of the RASSF10 candidate tumor suppressor gene is a frequent and an early event in gliomagenesis. Oncogene 30: 978-989, 2011.

27. Helmbold P, Richter AM, Walesch S, et al: RASSF10 promoter hypermethylation is frequent in malignant melanoma of the skin but uncommon in nevus cell nevi. J Invest Dermatol 132 687-694, 2012.
28. Livak KJ and Schmittgen TD: Analysis of relative gene expression data using real-time quantitative PCR and the 2(-Delta Delta C(T)) Method. Methods 25: 402-408, 2001.

29. Choi IS and Wu TT: Epigenetic alterations in gastric carcinogenesis. Cell Res 15: 247-254, 2005.

30. Kang GH, Lee S, Kim JS and Jung HY: Profile of aberrant CpG island methylation along multistep gastric carcinogenesis. Lab Invest 83: 519-526, 2003.

31. Sun Y, Deng D, You WC, et al: Methylation of p16 CpG islands associated with malignant transformation of gastric dysplasia in a population-based study. Clin Cancer Res 10: 5087-5093, 2004. 